“C 2016 IEEE. Personal use of this material is permitted. Permission from IEEE must be obtained for all other uses, in any current or future media, including reprinting/republishing this material for advertising or promotional purposes, creating new collective works, for resale or redistribution to servers or lists, or reuse of any copyrighted component of this work in other works." 


\title{
Development of A Model For sEMG based Joint- Torque Estimation using Swarm Techniques
}

\author{
${ }^{1} \mathrm{Ku}$ Nurhanim, ${ }^{1 *}$ I. Elamvazuthi, ${ }^{1}$ L.I. Izhar, ${ }^{2}$ T. Ganesan and ${ }^{3}$ S.W. Su \\ ${ }^{1}$ Department of Electrical \& Electronics Engineering \\ Universiti Teknologi PETRONAS, Malaysia \\ ${ }^{2}$ Tenaga Nasional Berhad Research, \\ Bandar Baharu Bangi, Selangor,Malaysia \\ ${ }^{3}$ University Technology Sydney, Australia \\ 1*Email: irraivan_elamvazuthi@petronas.com.my (Corresponding Author)
}

\begin{abstract}
Over the years, numerous researchers have explored the relationship between surface electromyography (sEMG) signal with joint torque that would be useful to develop a suitable controller for rehabilitation robot. This research focuses on the transformation of sEMG signal by adopting a mathematical model to find the estimated joint torque of knee extension. Swarm techniques such as Particle Swarm Optimization (PSO) and Improved Particle Swarm Optimization (IPSO) were adapted to optimize the mathematical model for estimated joint torque. The correlation between the estimated joint torque and actual joint torque were determined by Coefficient of Determination $\left(R^{2}\right)$ and fitness value of Sum Squared Error (SSE). The outcome of the research shows that both the PSO and IPSO have yielded promising results.
\end{abstract}

Keywords-Rehabilitation robot; EMG-based controller; Jointtorque estimation model; Swarm techniques.

\section{INTRODUCTION}

People lose their ability to walk when they suffer from a spinal cord injury, traumatic brain injury and stroke. Stroke is one of the leading causes of death worldwide including Malaysia [1]. According to 2014 statistics, 15497 people in Malaysia died due to stroke [2]. Stroke patients who lost their ability to move need to undergo rehabilitation training to recover their lost motor functionality for daily living. Many therapists are required for intensive conventional rehabilitation especially for lower limb recovery [3]. In recent years, rehabilitation robot has been developed by researchers to replace the conventional rehabilitation training effort of a therapist [4-5]. Major contribution of rehabilitation robots for the users is to enhance the recovery of muscle atrophy and improve the physiological state of the user by training them to adapt to normal daily motion environment [6].

Most of the studies considered that sEMG signal based control is able to provide an impressive development of rehabilitation robot [7-9]. Several researchers have developed rehabilitation robot for upper limb and lower limb such as neuro-fuzzy exoskeleton [10], SUEFUL-7 exoskeleton [11], NEUROexos [12], hand orthotic exoskeleton [13], XoR exoskeleton [14], TUPLEE exoskeleton [15] and Robot suit HAL (Hybrid Assistive Limb) [16]. The advantage of sEMG signals for rehabilitation robot is the patient's ability to control their own movement during training exercise. The sEMG signals will contribute as an information to estimate the intended movement but could not directly implemented into the controller of rehabilitation robot. The sEMG signals need to be converted to estimate joint torque/force and act as a feedback input or assistance trigger input of rehabilitation robot [17-19].

Several researchers have completed their studies on sEMG signal conversion to estimated joint torque or force by implementing the joint torque estimation model such as Hill Based Model [20-23], The Artificial Neural Network (ANN) [24-26] and mathematical model [29-32]. Hill Based Muscle Model is represented by contractile element, parallel elastic element and series elastic element which is related to physiological of human body. This model characterized the relationships of force length and force velocity to calculate the muscle force or torque. Researchers have done work for sEMG driven Hill Based model to estimate the joint torque of hip, knee and ankle, joint moment of ankle and joint torque of knee. The disadvantage of this model is that many parameters are needed to be validated at each time to provide optimal performance [20-23]. The ANN is a black box to model the non-linear relationship between sEMG signal and the desired joint torque. Several studies have implemented sEMG signals as an input of ANN and the output values are the predicted joint angle of ankle, joint torque of shoulder and elbow, and joint torque of knee and hip. The drawback of this model is the architecture of the ANN which is characterized by the number of weight and hidden layer that must be trained to minimize the validation error. This will cause inefficient computational time [24-27]. The alternative approach to sEMG conversion to estimated joint torque is by implementing the mathematical model. Researches have studied mathematical models by optimizing the unknown internal parameter of the mathematical model using Genetic Algorithm [28-29], Simulated Annealing [30], Levenberg Marquardt [31] and PSO algorithm [32] to calculate the joint torque close to desired joint torque.

This paper discusses the development of optimal mathematical model of sEMG for joint-torque estimation using particle swarm optimization (PSO) and improved particle swarm optimization algorithm (IPSO). 


\section{MATERIAL AND METHOD}

\section{A. Signal Processing}

Database of one healthy subject with three trials from [33] has been used as raw data of sEMG signals from 'vastus lateralis' muscles for movement task of knee extension $80^{\circ}$. Fig 1 shows the knee extension movement [34].

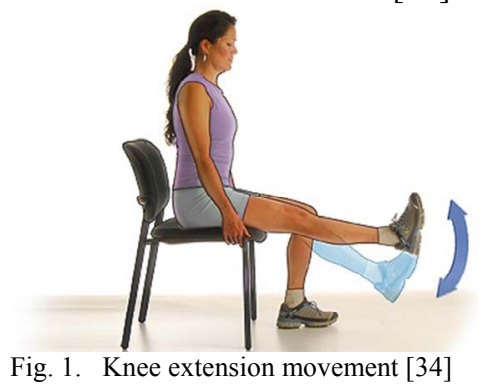

The database also provides the raw data of actual torque from torque sensor. Signal processing based analysis was carried out using the software, EMG Works Analysis ver. 4.07. Signal processing of sEMG signals are as follows:

\section{(i) Filtering}

The sEMG signals were then filtered by $4^{\text {th }}$ order Butterworth bandpass filter with the cutoff frequency bandwidth of $20 \mathrm{~Hz}-400 \mathrm{~Hz}$.

\section{(ii) Feature Extraction}

Time domain feature extraction: Root Mean Square (RMS) has been chosen as shown in Equation (1).

$$
\mathrm{RMS}=\sqrt{\frac{1}{N} \sum_{n=1}^{N} x_{n}^{2}}
$$

where, $x=$ sEMG signals data and $N=$ number of samples

\section{(iii) Muscle Activation}

This function uses a threshold value that can be set by the user to determine the active muscle region. The lowest value from sEMG signals are considered as noise level and the active region of muscles is the region which has RMS sEMG signal values that are greater than the noise level values.

\section{B. Joint Torque Estimation Model}

The mathematical models used in this research are expressed in Equations (2) to (5). The Equations (2) to (5) are chosen based on previous research works [28] and [31].

$$
M M_{(1)}=x_{1} \cdot u_{i}+x_{2} \cdot u_{i}^{\frac{1}{2}}
$$

$$
\begin{aligned}
& M M_{(2)}=x_{1} \cdot u_{i}^{x_{2}} \\
& M M_{(3)}=x_{1} \cdot u_{i}^{x_{2}}+x_{3} \cdot u_{i}^{x_{4}} \\
& M M_{(4)}=u_{i}^{x_{1}} \cdot e^{\left(x_{2}-x_{3} \cdot u_{i}\right)}
\end{aligned}
$$

where,

$$
\begin{aligned}
& M M_{(1)} \text { to } M M_{(4)}=\text { mathematical model for estimated } \\
& \text { joint torque } \\
& \begin{aligned}
& u_{i}=\text { processed sEMG data samples } \\
& x_{1}, x_{2}, x_{3} \text { and } x_{4}= \text { as random value parameter } \\
& \text { associated with the selected } \\
& \text { mathematical model }
\end{aligned}
\end{aligned}
$$

\section{Fitness Function}

A fitness function in Equation (6) is to measure the performance of each selected mathematical model from Equations (2) to (5). The fitness function is used to minimize the errors to determine the optimal value convergence of PSO and IPSO.

$$
S S E=\sum_{i=1}^{n}\left(T_{a c t(i)}-M M_{(y)(i)}\right)^{2}
$$

where,

$$
\begin{aligned}
& i=\text { data sample } \\
& S S E=\text { Sum Equared Error as fitness function } \\
& T_{a c t(i)}=\text { actual joint torque } \\
& M M_{(y)(i)}=\text { estimated joint torque using mathematical } \\
& \quad \text { model, } y=1,2,3 \text { and } 4
\end{aligned}
$$

\section{Implementation of Algorithm}

PSO and IPSO are implemented using $\mathrm{C}$ language of Bloodshed Dev $\mathrm{C}++$ version 4.9.9.2 on a personal computer with an Intel Core i3-231M@2.10 GHz processor and 4GB of memory. The sEMG signals are converted to the estimated joint torque using mathematical models of Equations (2) to (5) by optimizing the parameter values $\left(x_{i}\right)$ of each mathematical model with the execution of PSO and IPSO algorithms. PSO algorithm is a swarm technique that is inspired from the social behavior of a swarm of birds (particles) that search through a solution space. Each particle completes its own updating according to its current velocity and position. The best position can be derived from best personal particle position and global best particle position. The update velocity of particle is expressed as in Equation (7).

$v_{i}(t+1)=w v_{i}(t)+c_{1} r_{1}\left[\hat{x}_{i}(t)-x_{i}(t)\right]+c_{2} r_{2}\left[g(t)-x_{i}(t)\right]$

where $c_{1}$ and $c_{2}$ are acceleration constants for best personal particle position and the best global particle position respectively, and the range of the values between 0 to 2 . 
Random function $r_{1}$ and $r_{2}$ are random variables uniformly generated between 0 tol. Inertia weight coefficient $w$, serve as dampen of the velocities over the iteration. $v_{i}(t)$ and $x_{i}(t)$ are the particle velocity and particle position respectively, with respect to $(t)$ iteration. $\hat{x}_{i}(t)$ is the individual best particle position, $\mathrm{g}(t)$ is the best global particle position and $i$ is the number of particle. The update position of particle for PSO algorithm is expressed as in Equation (8) [35].

$$
x_{i}(t+1)=x_{i}(t)+v_{i}(t+1)
$$

The update position of particle equation implemented in IPSO algorithm is similar as PSO algorithm in Equation (8). On the other hand, the update velocity of particle equation for IPSO algorithm is implemented in Equation (9) proposed by Clec \& Kennedy [36]. In Equation 9, the inertia weight, (w), is replaced by contriction factor $(k)$, to eliminate the velocity clamping and encouraging convergence.

$$
v_{i}(t+1)=k\left[v_{i}(t)+c_{1} r_{1}\left[\hat{x}_{i}(t)-x_{i}(t)\right]+c_{2} r_{2}\left[g(t)-x_{i}(t)\right]\right]
$$

The flowchart of PSO and IPSO algorithm is illustrated in Fig. 2 and parameter setting of PSO and IPSO are provided in Tables 1 and 2 .

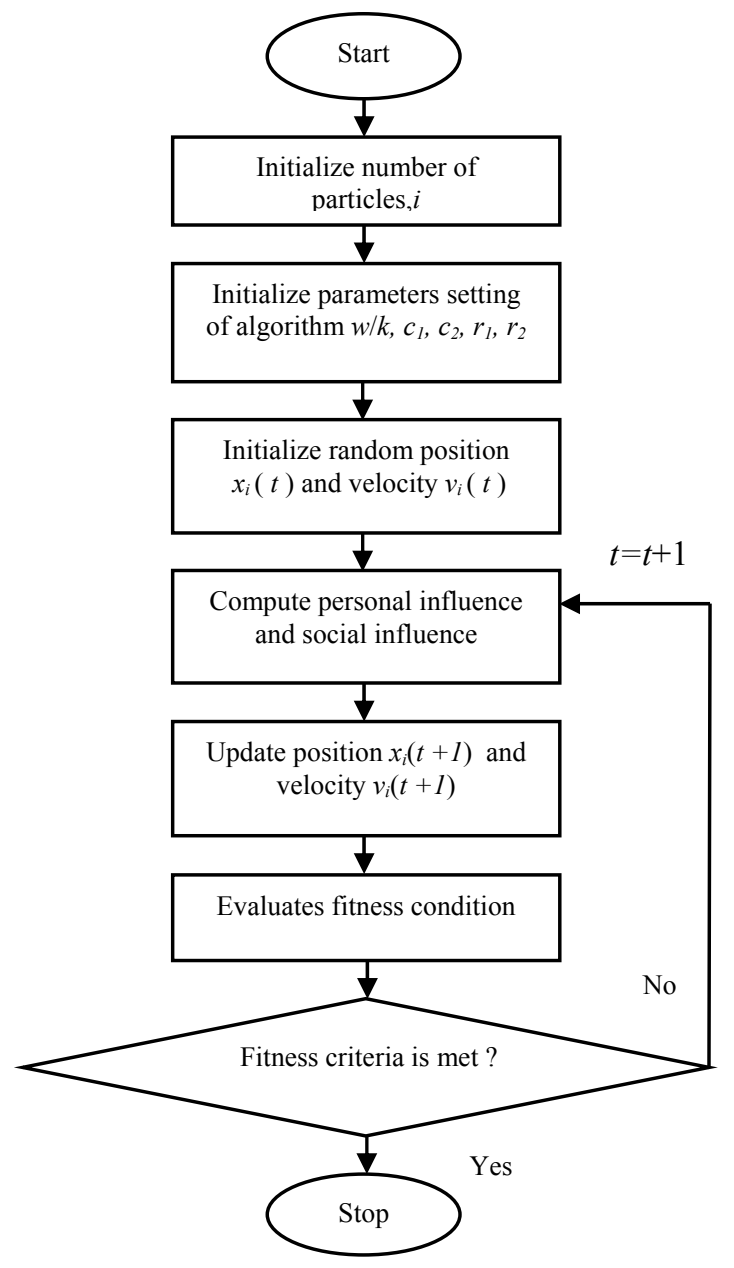

Fig. 2. Particle Swarm Optimization and Improvement Particle Swarm Optimization Algorithm flowchart

\begin{tabular}{lcccccc} 
& \multicolumn{7}{c}{ Table 1: PSO parameters setting } \\
\hline Model & $w$ & $c_{1}$ & $c_{2}$ & $r_{1}$ & $r_{2}$ & $i$ \\
\hline$M M_{(1)}$ & 0.625 & 1.7 & 2.0 & 0.5 & 0.5 & 10 \\
$M M_{(2)}$ & 0.625 & 1.7 & 2.0 & 0.5 & 0.5 & 10 \\
$M M_{(3)}$ & 0.625 & 1.2 & 1.7 & 0.5 & 0.5 & 10 \\
$M M_{(4)}$ & 0.625 & 1.2 & 1.5 & 0.5 & 0.5 & 10 \\
\hline
\end{tabular}

\begin{tabular}{ccccccc} 
& \multicolumn{7}{c}{ Table 2: IPSO parameters setting } \\
\hline Model & $k$ & $c_{1}$ & $c_{2}$ & $r_{1}$ & $r_{2}$ & $i$ \\
\hline$M M_{(1)}$ & 0.48 & 1.7 & 2.0 & 0.5 & 0.5 & 10 \\
$M M_{(2)}$ & 0.48 & 1.5 & 1.7 & 0.5 & 0.5 & 10 \\
$M M_{(3)}$ & 0.48 & 1.7 & 2.0 & 0.7 & 0.7 & 10 \\
$M M_{(4)}$ & 0.48 & 1.2 & 1.5 & 0.5 & 0.5 & 10 \\
\hline
\end{tabular}

\section{E. Performance Evaluation}

The correlation between the estimated joint torque and the actual joint torque are evaluated by Coefficient of Determination $\left(R^{2}\right)$ in Equation (10).

$$
R^{2}=\frac{\sum_{i=1}^{n}\left(M M_{(y)(i)}-\text { mean } T_{\text {act }(i)}\right)^{2}}{\sum_{i=1}^{n}\left(T_{a c t(i)}-M M_{(y)(i)}\right)^{2}+\sum_{i=1}^{n}\left(M M_{(y)(i)}-\text { mean } T_{\text {act }(i)}\right)^{2}}
$$

where,

$$
\begin{aligned}
& \begin{array}{l}
i=\text { data samples } \\
M M_{(y)(i)}=\text { estimated joint torque using mathematical } \\
\quad \text { models, } \mathrm{y}=1,2,3 \ldots \ldots \mathrm{n} \\
T_{\text {act }(i)}=\text { actual joint torque } \\
\text { mean__ } T_{\text {act }(i)}=\text { mean of actual joint torque }
\end{array}
\end{aligned}
$$

\section{RESULTS AND DISCUSSIONS}

Figures 3 to 6 represent the correlation graph between estimated joint torque and actual joint torque from mathematical models $M M_{(I)}$ to $M M_{(4)}$ for knee extension $80^{\circ}$ with IPSO algorithm. Table 3 illustrates the results of Coefficient of Determination $\left(R^{2}\right)$ for trial $1(\mathrm{~T} 1)$, trial $2(\mathrm{~T} 2)$ and trial 3 (T3) for each mathematical model equation.

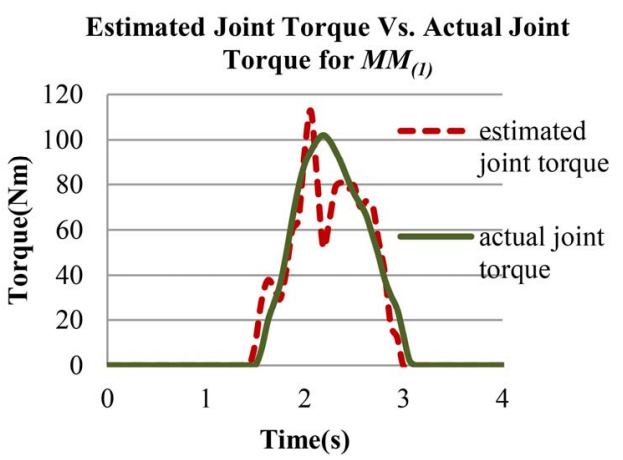

Fig. 3. Joint torques of knee extension $80^{\circ}$ without an external load for $M M_{(1)}$ 


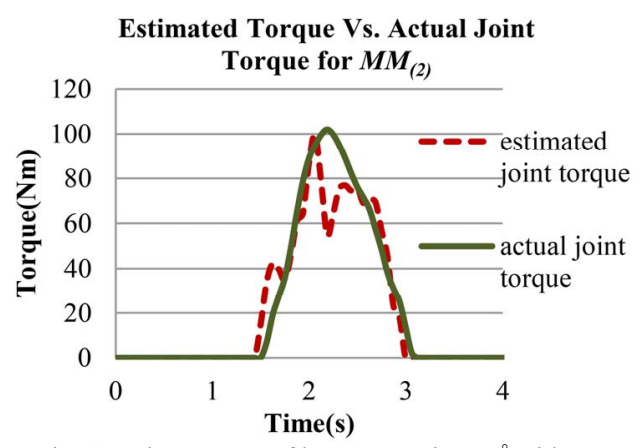

Fig. 4. Joint torques of knee extension $80^{\circ}$ without an external load for $M M_{(2)}$

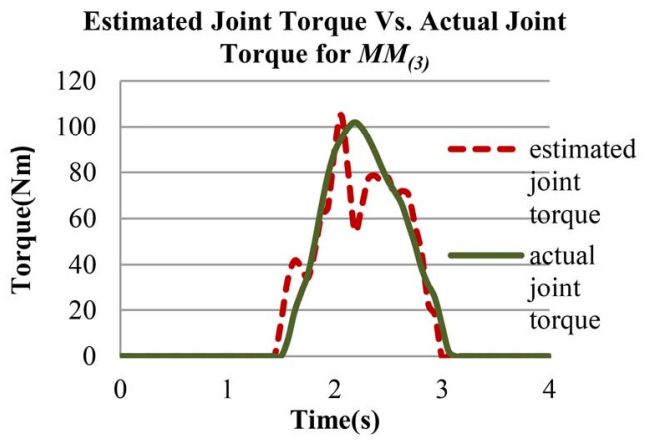

Fig. 5. Joint torques of knee extension $80^{\circ}$ without an external load for $M M_{(3)}$

Estimated Joint Torque Vs. Actual Joint Torque for $\boldsymbol{M M}_{(4)}$

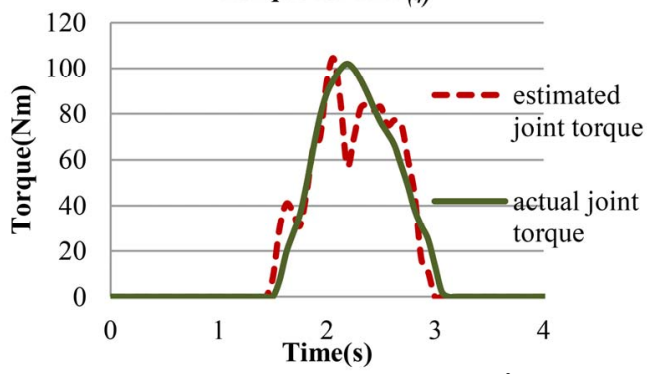

Fig. 6. Joint torques of knee extension $80^{\circ}$ without an external load for $M M_{(4)}$

Table 3: Results of Coefficient of Determination $\left(R^{2}\right)$ of PSO and IPSO for knee extension $80^{\circ}$

\begin{tabular}{lcccc}
\hline & \multicolumn{4}{c}{ Coefficient of Determination $\left(R^{2}\right)$} \\
\hline Model & T1 & T2 & T3 & mean \pm std \\
$M M_{(1)}$ & 0.92 & 0.83 & 0.86 & $0.87 \pm 0.04$ \\
$M M_{(2)}$ & 0.92 & 0.84 & 0.86 & $0.87 \pm 0.04$ \\
$M M_{(3)}$ & 0.92 & 0.84 & 0.86 & $0.87 \pm 0.04$ \\
$M M_{(4)}$ & 0.92 & 0.85 & 0.86 & $0.88 \pm 0.04$ \\
\hline
\end{tabular}

As shown in Table 3, the results of Coefficient of Determination $\left(R^{2}\right)$ are similar for PSO and IPSO algorithm. It can be observed that mathematical model $M M_{(4)}$ has the highest mean \pm std value with $R^{2}$ equals to $0.88 \pm 0.04$ compared to mathematical models of $M M_{(1)}, M M_{(2)}$ and $M M_{(3)}$ with mean \pm std value of $R^{2}, 0.87 \pm 0.04$. These results established mathematical model $M M_{(4)}$ as the optimal mathematical model compared to mathematical models $M M_{(1)}, M M_{(2)}$ and $M M_{(3)}$. However, the SSE and execution time of IPSO algorithm obtained better results compared to the PSO algorithm as shown in Tables 4 and 5. Fig. 7 illustrates an example graph of the SSE with respect to the number of iterations for knee extension $80^{\circ}$ by comparing PSO and IPSO algorithm of $M M$ (4).

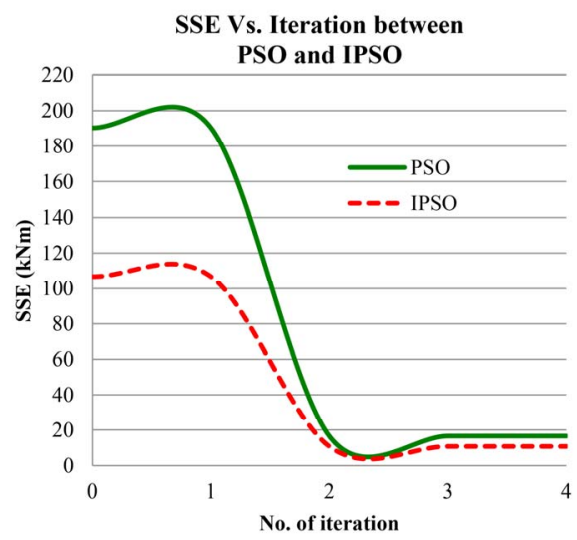

Fig.7 Comparison of PSO and IPSO of the SSE with respect to the number of iterations for knee extension $80^{\circ}$

The results of PSO and IPSO algorithm for SSE, number of iterations and execution time are represented in Tables 4 and 5 for each mathematical model for trial 1(T1), trial 2 (T2) and trial 3 (T3), of knee extension $80^{\circ}$.

\begin{tabular}{lcccc}
\multicolumn{5}{c}{ Table 4: Comparison between IPSO and PSO for SSE } \\
of knee extension $80^{\circ}$ \\
\hline \multicolumn{5}{c}{ Sum Squared Error(SSE)-(Nm) } \\
\hline Model & Algorithm & T1 & T2 & T3 \\
$M M_{(1)}$ & IPSO & 6779.24 & 12794.20 & 12509.20 \\
& PSO & 8669.91 & 13544.40 & 15590.40 \\
& IPSO & 6999.71 & 11473.30 & 12265.20 \\
$M M_{(2)}$ & PSO & 8998.30 & 14046.20 & 25330.10 \\
& IPSO & 6793.63 & 13104.20 & 12628.60 \\
$M M_{(3)}$ & PSO & 6805.70 & 52554.5 & 13178.90 \\
& IPSO & 5954.31 & 10752.80 & 11099.90 \\
$M M_{(4)}$ & PSO & 6148.26 & 16427.7 & 11177.1 \\
\hline
\end{tabular}

Table 5: Comparison between IPSO and PSO for number of iterations and execution time of knee extension $80^{\circ}$

\begin{tabular}{cccccc}
\hline Model & Algorithm & $\begin{array}{c}\text { No. of } \\
\text { Iteration }\end{array}$ & $\begin{array}{c}\text { Execution } \\
\text { time(s) }\end{array}$ & $\begin{array}{c}\text { No. of } \\
\text { Iteration }\end{array}$ & $\begin{array}{c}\text { Execution } \\
\text { time(s) }\end{array}$ \\
\hline \multirow{3}{*}{$M M_{(1)}$} & IPSO & 20 & 1.96 & 2 & 0.83 \\
& PSO & 20 & 3.21 & 16 & 3.87 \\
$M M_{(2)}$ & IPSO & 2 & 1.56 & 2 & 1.89 \\
& PSO & 2 & 2.49 & 2 & 2.43 \\
$M M_{(3)}$ & IPSO & 2 & 0.93 & 2 & 3.02 \\
& PSO & 52 & 3687.35 & 8 & 18.31 \\
$M M_{(4)}$ & IPSO & 4 & 0.87 & 4 & 1.05 \\
& PSO & 4 & 2.53 & 4 & 6.31 \\
\hline
\end{tabular}


Continued Table 5: Comparison between IPSO and PSO for number of iterations and execution time of knee extension $80^{\circ}$

\begin{tabular}{cccc}
\hline Model & Algorithm & $\begin{array}{c}\text { No. of } \\
\text { Iteration }\end{array}$ & $\begin{array}{c}\text { Execution } \\
\text { time(s) }\end{array}$ \\
\hline \multirow{3}{*}{$M M_{(1)}$} & IPSO & 2 & T3 \\
& PSO & 38 & 7.63 \\
$M M_{(2)}$ & IPSO & 2 & 2.42 \\
& PSO & 4 & 50.57 \\
$M M_{(3)}$ & IPSO & 2 & 0.84 \\
& PSO & 2 & 3.30 \\
$M M_{(4)}$ & IPSO & 4 & 1.66 \\
& PSO & 4 & 1.87 \\
\hline
\end{tabular}

From Table 4, it can be observed that the fitness value from the sum squared error of IPSO is less than the sum squared error of PSO. Besides that, the execution time of IPSO is faster than PSO as represented in Table 5. The update velocity of particle equation for IPSO replaces the inertia weight $(w)$ with the constriction factor $(k)$ to control the convergence tendency and eliminate some optimization problem in particle swarm algorithm. In this paper, the sEMG signals are applied as an input to the mathematical models and the unknown parameter values in the mathematical models were optimized using PSO and IPSO algorithm. From the analysis, it can be identified that the sEMG signals have a good fit with the mathematical models to yield the estimated joint torque.

\section{CONCLUSION}

In this study, four mathematical models have been tested and it was found that mathematical model $M M_{(4)}$ can be construed as the optimal mathematical model for PSO and IPSO algorithm. The outcome of the research could be used as an EMG-based controller for rehabilitation robots. In future, the results could be improved by investigating other feature extraction techniques.

\section{REFERENCES}

[1] D. Mozaffarian, E. J. Benjamin, A. S. Go, D. K. Arnett, M. J. Blaha, M. Cushman, S. R. Das, S. de Ferranti, J. P. Despr??s, H. J. Fullerton, V. J. Howard, M. D. Huffman, C. R. Isasi, M. C. Jim??nez, S. E. Judd, B. M. Kissela, J. H. Lichtman, L. D. Lisabeth, S. Liu, R. H. Mackey, D. J. Magid, D. K. McGuire, E. R. Mohler, C. S. Moy, P. Muntner, M. E. Mussolino, K. Nasir, R. W. Neumar, G. Nichol, L. Palaniappan, D. K. Pandey, M. J. Reeves, C. J. Rodriguez, W. Rosamond, P. D. Sorlie, J. Stein, A. Towfighi, T. N. Turan, S. S. Virani, D. Woo, R. W. Yeh, and M. B. Turner, Heart Disease and Stroke Statistics 2016 Update: A Report From the American Heart Association. 2015.

[2] www.worldlifeexpentency.com/country_health_profile/Malaysia, downloaded on $15^{\text {th }}$ July 2016.

[3] G. Gelderblom and M. De Wilt, "Rehabilitation robotics in robotics for healthcare; a roadmap study for the European Commission," IEEE $11^{\text {th }}$ Conf. on Rehabilitation Robotics, pp. 834-838, 2009.

[4] R. Singh and S. Chatterji, "Trends and Challenges in EMG Based Control Scheme of Exoskeleton Robots-A Review," Int. J. Sci. Eng. Res., vol. 3, no. 8, pp. 1-8, 2012.

[5] A. Gupta and M. K. O. Malley, "Robotic Exoskeletons for Upper
Extremity Rehabilitation," Rehabil. Robot., Edi. Sashi S.Kommu, pp. 371-396, 2006.

[6] B. Singh, R. Ashish, S. Gurvinder, and S. Virk, "Lower Limb Exoskeletons: A Brief Review Lower Limb Exoskeletons: A Brief Review," Conf. on Mech. Eng. \& Tech.(COMET) 2016 pp. 18-24, 2016.

[7] M. Asghari Oskoei and H. Hu, "Myoelectric control systems-A survey," Biomed. Signal Process. Control, vol. 2, no. 4, pp. 275-294, 2007.

[8] K. Kiguchi and Y. Hayashi, "An EMG-based control for an upper-limb power-assist exoskeleton robot," IEEE Trans. Syst. Man, Cybern. Part B Cybern., vol. 42, no. 4, pp. 1064-1071, 2012.

[9] I. Elamvazuthi, K. A. R. K. Nurhanim, P. Vasant, S. Parasuraman, Z. Zulika, and G. A. Ling, "Surface Electromyogram ( sEMG ) Detection and Analysis in the Development of an Exoskeleton Control System ," 2012 Australian Control Conf. pp. 197-202, 2012.

[10] K. Kiguchi, T. Tanaka, and T. Fukuda, "Neuro-fuzzy control of a robotic exoskeleton with EMG signals," IEEE Trans. Fuzzy Syst., vol. 12, no. 4, pp. 481-490, 2004.

[11] R. A. R. C. Gopura, K. Kiguchi, and Y. Yi, "SUEFUL-7: A 7DOF upper-limb exoskeleton robot with muscle-model-oriented EMG-based control," 2009 IEEE/RSJ Int. Conf. Intell. Robot. Syst. IROS 2009, pp. 1126-1131, 2009.

[12] T. Lenzi, S. M. M. De Rossi, N. Vitiello, and M. C. Carrozza, "Proportional EMG control for upper-limb powered exoskeletons," Proc. Annu. Int. Conf. IEEE Eng. Med. Biol. Soc. EMBS, pp. 628-631, 2011.

[13] M. Dicicco, L. Lucas, Y. Matsuoka, and M. Engineering, "Comparison of Control Strategies for an EMG Controlled Orthotic Exoskeleton for the Hand," Int. Conf. Robot. Autom., no. April, pp. 1622-1627, 2004.

[14] J. Morimoto, T. Noda, and S. H. Hyon, "Extraction of latent kinematic relationships between human users and assistive robots," Proc. - IEEE Int. Conf. Robot. Autom., pp. 3909-3915, 2012.

[15] C. Fleischer and G. Hommel, "A human-exoskeleton interface utilizing electromyography," IEEE Trans. Robot., vol. 24, no. 4, pp. 872-882, 2008.

[16] H. Kawamoto, S. Taal, H. Niniss, T. Hayashi, K. Kamibayashi, K. Eguchi, and Y. Sankai, "Voluntary motion support control of Robot Suit HAL triggered by bioelectrical signal for hemiplegia," 2010 Annu. Int. Conf. IEEE Eng. Med. Biol. Soc. EMBC'10, pp. 462-466, 2010.

[17] C. Fleischer, "Controlling Exoskeletons with EMG signals and a Biomechanical Body Model," Dissertation of Technische Universitat Berlin, 2007.

[18] R. Song, K. Y. Tong, X. Hu, and L. Li, “Assistive control system using continuous myoelectric signal in robot-aided arm training for patients after stroke," IEEE Trans. Neural Syst. Rehabil. Eng., vol. 16, no. 4, pp. 371-379, 2008.

[19] H. I. Krebs, J. J. Palazzolo, L. Dipietro, M. Ferraro, J. Krol, K. Rannekleiv, B. T. Volpe, and N. Hogan, "Rehabilitation robotics: Performance-based progressive robot-assisted therapy," Auton. Robots, vol. 15 , no. 1, pp. 7-20, 2003.

[20] M. Sartori, M. Reggiani, C. Mezzato, and E. Pagello, "A Lower Limb EMG-driven Biomechanical Model for Applications in Rehabilitation Robotics," Int. Conf. Adv. Robot., pp. 1-7, 2009.

[21] R. A. Bogey, J. Perry, and A. J. Gitter, "An EMG-to-force processing approach for determining ankle muscle forces during normal human gait," IEEE Trans. Neural Syst. Rehabil. Eng., vol. 13, no. 3, pp. 302$310,2005$.

[22] C. Fleischer and G. Hommel, "Calibration of an EMG-based body model with six muscles to control a leg exoskeleton," Proc. - IEEE Int. Conf. Robot. Autom., pp. 2514-2519, 2007.

[23] Y. GAO, S. WANG, F. XIAO, and J. ZHAO, "An Angle-EMG Biomechanical Model of the Human Elbow Joint," J. Mech. Med. Biol., vol. 16, no. 2, p. 1650078-1-1650078-21, 2016.

[24] S. K. Au, P. Bonato, and H. Herr, "prosthesis : An initial experimental study," Signal Processing, pp. 375-379, 2005.

[25] C. Loconsole, S. Dettori, A. Frisoli, C. A. Avizzano, and M. Bergamasco, "An EMG-based approach for on-line predicted torque control in robotic-assisted rehabilitation," IEEE Haptics Symp. HAPTICS, pp. 181-186, 2014. 
[26] S. Kawai, K. Naruse, H. Yokoi, and Y. Kakazu, "A study for control of a power assist device," 2004 IEEE/RSJ Int. Conf. Intell. Robot. Syst. (IEEE Cat. No.04CH37566), vol. 3, pp. 2283-2288, 2004.

[27] L. Peng, Z. G. Hou, and W. Wang, "A dynamic EMG-torque model of elbow based on neural networks," Proc. Annu. Int. Conf. IEEE Eng. Med. Biol. Soc. EMBS, vol. 2015-November, pp. 2852-2855, 2015.

[28] S.Parasuraman and A. W. Oyong, "Robot-Assisted Stroke Rehabilitation: Joint Torque/Force Conversion From Emg Using GA Process," J. Mech. Med. Biol., vol. 11, no. 04, pp. 827-843, 2011.

[29] Ku Nurhanim, I. Elamvazuthi, P. Vasant, and S. Parasuraman, "Determination of Mathematical Model and Torque Estimation of sEMG Signals based on Genetic Algorithm," Int. J. of Sci. \& Eng. Research, vol. 4, no. 5, pp. 135-139, 2013.

[30] A. W. Oyong, S. Parasuraman, and V. L. Jauw, "Estimation of muscle forces and joint torque from EMG using SA process," Proc. 2010 IEEE EMBS Conf. Biomed. Eng. Sci. IECBES 2010, pp. 81-86, 2010.

[31] K. Ullah and J. Kim, "A Mathematical Model for Mapping EMG Signal to Joint Torque for the Human Elbow Joint using Nonlinear Regression," Prof. Int. Conf. Autons. Robots and Agents 2009, pp. 103$108,2009$.

[32] Ku Nurhanim, I. Elamvazuthi, P. Vasant, T. Ganesan, S. Parasuraman, and M. K. A. Ahamed Khan, "Joint torque estimation model of surface electromyography(sEMG) based on swarm intelligence algorithm for robotic assistive device," Procedia Comput. Sci., vol. 42, pp. 175-182, 2014.

[33] www.isb.org/datasource.html,downloaded $19^{\text {th }}$ June 2016

[34] R. C. Eberhart and Y. Shi, "Particle swarm optimization: developments, applications and resources," Proc. 2001 Congr. Evol. Comput. (IEEE Cat. No.01TH8546), vol. 1, pp. 81-86, 2001.

[35] https://myhealth.alberta.ca/Health/_layouts/15/healthwise/media/hw/ h9991476_001_1.jpg.

[36] M. Clerc and J. Kennedy, "The particle swarm-explosion, stability, and convergence in a multidimensional complex space," IEEE Trans. Evol. Comput., vol. 6, no. 1, pp. 58-73, 2002. 